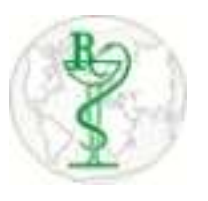

INDO GLOBAL JOURNAL OF

PHARMACEUTICAL SCIENCES

ISSN 2249- 1023

\title{
Chronic Alcoholism and Dependence: A Case Study
}

\author{
Priya Mishra ${ }^{1}$, Seema Upadhyay ${ }^{1}$, Shikha Pandey ${ }^{1}$, Smriti Khatri ${ }^{2 *}$ \\ ${ }^{I}$ Spectrum Institute of Pharmaceutical Sciences and Research, Greater Noida \\ ${ }^{2}$ Tulasi Psychiatric and Rehabilitation Centre, Delhi
}

\begin{abstract}
Address for
Correspondance

Smriti Khatri,

smritidua3@gma

il.com

Received:

28.11.2017

Accepted:

14.12.2017

ABSTRACT: Addictive behaviour associated with alcoholism is a public health problem and needs consideration due to social, work, family, physical, legal and violence-related risks. The research on alcoholism has mainly focused on the identification of brain mechanisms which support the fortifying activities of alcohol and the progression of changes in neural function which may lead to the development of dependence. The results had shown that addictive behaviour related to alcoholism is responsible for suffering to family members, interpersonal conflicts, domestic violence, parental inadequacy, child abuse, negligence, financial and legal difficulties, in addition to clinical problems associated with it. This study is aimed to observe the impact of alcoholism on family relations and health of the patient and the case management by the sessions on psycho education, motivation enhancement therapy, brief intervention, elapse prevention therapy, pre-discharge counselling, discharge counselling and social group work. (C) 2018 iGlobal Research and Publishing Foundation. All rights reserved.
\end{abstract}

Keywords Alcoholism; Relations; Brain Mechanisms; Clinical Problems.

\section{INTRODUCTION}

Alcoholic consumption has been an integral part of social lifestyle for centuries and societies have constantly found it hard to restrain their use. This article displays a case study of patient with alcohol dependence syndrome. Psycho education alongside pharmacotherapy was given to the patient concentrating on building inspiration for recovery [1]. The world's third biggest hazard factor for illness is alcohol consumption. Alcohol is a causal factor in 60 types of diseases and injuries and a component cause in 200 others. The harmful use of alcohol results in net troll of 2.5 million deaths every year. Almost $4 \%$ of all deaths worldwide are ascribed to alcohol which are more noteworthy than deaths caused by HIV/AIDS, violence or tuberculosis. Numerous genuine social issues including violence, child neglect, abuse, and absenteeism in the workplace are also associated with alcohol consumption [2]. Cessation of alcoholism is very difficult and characterised by chronic relapsing disorder. Addiction of alcohol is defined by compulsive preoccupation for obtaining alcohol as well as loss of control over consumption Development of tolerance and dependence as well as impaired social and occupational functioning are also its side effects [3]. Chronic alcoholism is a pathological condition resulting from the habitual use of alcohol in excessive amounts. Symptoms of the disease include anorexia, diarrhoea, weight loss neurologic and psychiatric disturbances and fatty deterioration of liver leading to cirrhosis [4]. Chronic alcoholism needs treatment to reduce health risks and craving for alcohol. The treatments for the disease like liver cirrhosis and different types of cancer are poorly developed. This makes the 'risk factor control' a better option. After proper treatment the patient not only improves his physical and mental status but also returns normal to day to day life. Alcohol consumption is the third largest risk factor for development of various diseases like liver cirrhosis, anaemia in developed countries $[5,6]$. 


\section{Indo Global Journal of Pharmaceutical Sciences, 2018; 8(1): 9-11}

\section{PRESENTATION OF CASE}

A 65 yr old Ex Air Force employee from Gurugram married from last $40 \mathrm{yrs}$ having no family history of alcohol dependence, was admitted to Tulasi Psychiatric Centre, New Delhi for treatment of alcoholic dependence. The patient was apparently maintaining well till 30 years back when he started consuming alcohol under the influence of friend in a controlled manner. For the initial $10-15$ years, he drank once in a while or occasionally. After 10-15 years the amount of the alcohol consumption increased and duration gap decreased. $\mathrm{He}$ started it on daily basis gradually. After some time, he started drinking regularly along with tobacco or cigarettes. He started having behavioural changes and effected biological symptoms, due to regular and excessive consumption of alcohol. Patient started getting easily irritated and abusive on very small things. He started getting anger outburst at some time. Patient was also facing many physical complications like improper sleep, loss of appetite and mood swings. At present, he is not getting proper sleep from more than 2 years, his appetite got severely decreased. Due to the guilt feelings and negative thoughts, he had tried 3-4 times overdose of sleeping pills. He used to get emotional very easily in abstinence of alcohol and his daily routine was getting gradually impaired. So his family decided to get him admitted in rehabilitation centre for the treatment.

\section{PSYCHOTHERAPY}

Psychotherapy is a process in which the therapist imparts knowledge of illness and its related aspect to the family and which continual assistance help the family to implement better coping skills and other preferred interaction with the affected member. Mental status examination revealing patient was cooperative, touch with surrounding was present, normal psychomotor activity, in speech, and it was relevant coherent and goal directed.

Psychotherapy sessions were divided into 12 steps programme including literature of addiction, life history writing, written tasks, family and individual sessions etc. Initial session was focused on assessing the knowledge of patient regarding the illness. Later the symptoms associated with the illness were explained. The harmful effects of substance use and its implications on patient's physical, emotional, familial, and social life were also discussed.

\section{Motivational Enhancement Therapy (MET):}

Motivational interviewing is a systematic intervention approach based on principles of motivational psychology, designed to produce rapid, internally motivated changes. The patient was exposed to motivation enhancement and relapse prevention therapy. A baseline assessment on understanding the drinking pattern, concept of disorder, medical model, science of addiction, abstinence period, locus of control, coping pattern, internal relationship problems and patient's attitude towards drinking were assessed. Therapist recognized the patient efforts, appreciated his strengths and gives feedbacks. Simultaneously psycho education and supportive therapy helped him realized the negative effects of alcohol. This increases his readiness to change. Change plan worksheet was discussed. Patient was also asked to identify and discuss the strategies to prevent relapse. The cognitive model of relapse, categories of relapse cause have explained to the patient like peers influence, external situations and emotional cause. Importance of identifying relapse triggers was discussed so that the triggers can be identified and prevented. Follow-up sessions with routine management were explained to the patient after discharge.

The psycho social intervention was provided to the patients and his family members. Sessions were conducted on admission counseling, family intervention and supportive therapy. The sessions on psycho education, motivation enhancement therapy, brief intervention, elapse prevention therapy, pre-discharge counseling, discharge counseling and social group work were also conducted. At the end of the therapy, the client had improved the knowledge about the illness and his motivation level was also increased to action phase and achieved the coping skills to recover from relapse.

\section{ACKNOWLEDGEMENT}

Tulasi Psychiatric and rehabilitation centre would like to thank Spectrum Institute of Pharmaceutical Sciences and Research, Greater Noida for the support in preparation of this manuscript.

\section{REFERENCES}

1. Suman Borah, Arif Ali, A case study of person with alcohol dependence syndrome with poor motivation, Int. Res. J. Social Sci., 2016, Vol. 5(3), 74-79.

2. http://www.who.int/topics/alcohol_drinking/en/ on 14 November 2017.

3. Weiss F, Porrino LJ. Behavioral neurobiology of alcohol addiction: recent advances and challenges. Journal of Neuroscience. 2002; 1; 22 (9): 3332-7.

4. Frezza M, Padova C, Terpin M. The role of decreased gastric alcohol dehydrogenase activity and first-pass metabolism. New England Journal of Medicine. 1990; 322(2): 95-99

5. Rupinder Kaur, Dr. Manish Sinha. Drugs for chronic alcoholism and their quantitative estimation, World 
Indo Global Journal of Pharmaceutical Sciences, 2018; 8(1): 9-11

Journal of Pharmaceutical Research, 2015; Volume 4, Issue 9, 2879-2890.,

6. Klatsky AL. Cardiovascular effects of alcohol. Scientific

American Science and Medicine., 1995; 2(2): 228-337

Indo Global Journal of Pharmaceutical Sciences( ISSN 22491023 ; UGC Journal No.: 44477; CODEN- IGJPAI; NLM ID: 101610675) indexed and abstracted in EMBASE(Elsevier), UGC Journal List, National Library of Medicine (NLM) Catalog, Elsevier( EMBASE), ResearchGate, Publons, CAS (ACS), Index Copernicus, Google Scholar and many more. For further details, visit http://iglobaljournal.com 